\title{
SOLUBLE MILK PROTEINS IMPROVE MUSCLE MASS RECOVERY AFTER IMMOBILIZATION-INDUCED MUSCLE ATROPHY IN OLD RATS BUT DO NOT IMPROVE MUSCLE FUNCTIONAL PROPERTY RESTORATION
}

\author{
J. VERNEY ${ }^{1}$, V. MARTIN ${ }^{1}$, S. RATEL ${ }^{1}$, V. CHAVANELLE ${ }^{1}$, M. BARGETTO ${ }^{1}$, M. ETIENNE ${ }^{1}$, \\ E. CHAPLAIS ${ }^{1}$, P. LE RUYET ${ }^{2}$, C. BONHOMME ${ }^{2}$, L. COMBARET ${ }^{3}$, C. GUILLET ${ }^{3,4}$, N. BOISSEAU ${ }^{1}$, \\ P. SIRVENT ${ }^{1}$, D. DARDEVET ${ }^{3}$
}

1. Clermont Université, Université Blaise Pascal, EA 3533, Laboratoire des Adaptations Métaboliques à l'Exercice en Conditions Physiologiques et Pathologiques, CRNH Auvergne, Clermont Ferrand; 2.Lactalis Recherche et Développement, Lactalis Nutrition Santé, France; 3. INRA, Unité de Nutrition Humaine (UNH, UMR 1019), CRNH Auvergne, France;

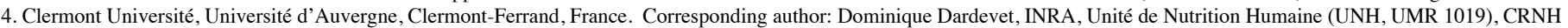
Auvergne, France, dominique.dardevet@clermont.inra.fr

\begin{abstract}
Objectives: Effect of 3 different dairy protein sources on the recovery of muscle function after limb immobilization in old rats. Design: Longitudinal animal study. Setting: Institut National de la Recherche Agronomique (INRA). The study took part in a laboratory setting. Intervention: Old rats were subjected to unilateral hindlimb immobilization for 8 days and then allowed to recover with 3 different dietary proteins: casein, soluble milk proteins or whey proteins for 49 days. Measurements: Body weight, muscle mass, muscle fibre size, isometric, isokinetic torque, muscle fatigability and muscle oxidative status were measured before and at the end of the immobilization period and during the recovery period i.e 7, 21, 35 and 49 days post immobilization. Results: In contrast to the casein diet, soluble milk proteins and whey proteins were efficient to favor muscle mass recovery after cast immobilization during aging. By contrast, none of the 3 diary proteins was able to improve muscle strength, power and fatigability showing a discrepancy between the recovery of muscle mass and function. However, the soluble milk proteins allowed a better oxidative capacity in skeletal muscle during the rehabilitation period. Conclusion: Whey proteins and soluble milk proteins improve muscle mass recovery after immobilization-induced muscle atrophy in old rats but do not allow muscle functional property restoration.
\end{abstract}

Key words: Aging, immobilization, muscle mass recovery, muscle function, whey proteins.

\section{Introduction}

Sarcopenia is a highly predictive factor of frailty, of limited mobility, of increased susceptibility to injury and of impaired recovery (1). Besides a chronic and progressive muscle loss, sarcopenia could be also explained by an impaired recovery of muscle mass after a catabolic state including immobilizationinduced muscle atrophy (2-6). We and others have shown that muscle protein synthesis was impaired during the recovery period $(4,7)$ which may explain the absence of a positive nitrogen balance and subsequently the lack of muscle mass recovery observed during aging (5-6). These episodes of uncomplete recoveries repeated over time may contribute to a significant muscle mass and strength losses and then worsen the sarcopenic state. This phenomenon named the "acute catabolic crisis" model (8) contributes to accelerate the frailty syndrome appearance and increases the risk of early institutionalisation and death (9-10). The "acute catabolic crisis" model has also been observed after other generalized catabolic states including food deprivation or glucocorticoid treatment (11-13).

Muscle protein synthesis is not constant during the day and is subjected to variations especially following food intake. Dietary amino acids are particularly efficient in stimulating muscle protein synthesis and in inhibiting muscle protein breakdown (14-16), hence resulting in a positive post-prandial nitrogen balance required to maintain the muscle mass Received June 24, 2016

Accepted for publication September 12, 2016 constant. Among amino acids, leucine is particularly known for its 'signal' properties i.e. to acutely increase muscle protein synthesis and decrease protein breakdown under both in vitro and in vivo conditions (17-26). Leucine ingestion results in the phosphorylation of proteins that are critical for the anabolic mTOR signalling pathway, thereby leading to the stimulation of the initiation of muscle protein synthesis (27-29). We have shown (5) that muscle protein synthesis becomes resistant to the anabolic effect of food intake during the immobilization and recovery period even if the protein intake is considered sufficient to cover the amino acids requirements in a control non-pathological situation. This anabolic resistance has been associated to an elevation of the muscle anabolic threshold which controls the intensity and the duration of post-prandial muscle protein synthesis (30). However, in a recent study in aged rats (5), we showed that leucine rich soluble milk proteins were more efficient than a standard diet to stimulate postprandial muscle protein synthesis in a limb that was previously immobilized and were then efficient to improve muscle mass recovery. So far, the great majority of nutritional interventions aimed at targeting muscle mass recovery after a period of immobilization. However, these nutritional interventions should also target muscle functional properties, since muscle mass and force/power production capacities are not always linearly related (31-33). Interestingly, in adults, leucine rich soluble milk proteins also promoted a faster recovery of 
isometric force and concentric power output (34). Whether soluble milk proteins may improve simultaneously muscle mass and functional properties recovery after unloading in elderly remains unknown. Indeed, this remained questionable as a recent systematic review and meta-analysis concluded that leucine rich protein supplementation was found to exert beneficial effects on lean body mass in sarcopenic older persons but not on muscle strength (35). In addition, the quality of the leucine rich milk proteins could also be of importance. Soluble milk proteins (directly extracted from milk using membrane technologies at low temperature (microfiltration and ultrafiltration)) seemed more efficient than whey proteins (extracted after casein coagulation) in increasing muscle concentric power during the recovery period in adults (36). The reason of these differences between the sources of proteins (directly extracted from milk by ultrafiltration or from whey) remains obscure but a differential impact on the oxidative status of the skeletal muscle could be hypothesized since Gryson et al. (37) showed that muscle resistance to fatigue with soluble milk proteins was improved in elderly.

The aim of the present study was to compare the beneficial effect of three milk proteins i.e. casein, soluble milk proteins and whey proteins on the recovery of skeletal muscle mass, force, power and fatigability after cast immobilisation during aging.

\section{Materials and Methods}

\section{Animals and experimental design - ethics statement}

The present study was approved by the Animal Care and Use Committee of Auvergne (CEMEA Auvergne; Permit Number: CE108-12) and the Ministère de l'Enseignement Supérieur et de la Recherche ( $\mathrm{n}^{\circ}$ 01075.02). Old adult male Wistar rats (20-21 months) were housed individually under controlled environmental conditions (room temperature $22^{\circ} \mathrm{C} ; 12 \mathrm{~h}$ lightdark cycle, light period starting at 08:00 h), fed ad libitum a standard $13 \%$ casein diet (Table 1) and given free access to water. After a 3-week adaptation period (I0), the rats were subjected to unilateral hindlimb cast immobilization with an Orfit-soft plaque (Gibaud, France) for 8 days (I8). The foot was positioned in plantar flexion to induce a maximal atrophy of the gastrocnemius muscle (4). As casted rats reduced their food intake during the immobilization period, control non-casted rats were pair-fed $(\mathrm{PF})$ to the casted groups at each time point studied and were fed the standard $13 \%$ casein diet. To allow muscle recovery, casts were removed and animals were studied at cast removal (I8) and then 7 (R7), 21 (R21), 35 (R35) and 49 (R49) days after cast removal (Figure 1A and B). During the recovery period, the animals were fed either the standard $13 \%$ casein diet (CAS), the $13 \%$ soluble milk proteins diet (PRO) or the $13 \%$ whey proteins diet (LAC) (Table 1, Figure 1). The protein sources differed from their digestion speed characteristics and leucine content (CAS (slow digested, poor in leucine) vs. PRO and LAC (fast digested and rich in leucine) and also from different milk process (PRO (filtration) vs. CAS and LAC (precipitation)).

\section{Table 1}

Composition of the experimental diets in g per kg dry matter. Cysteine and proline were added to the CAS and PRO, LAC diets, respectively, in order to match amino-acid composition between all experimental diets

\begin{tabular}{lccc}
\hline g/kg diet & CAS & PRO & LAC \\
\hline Caseinate Ca2+ & 156 & 0 & 0 \\
Soluble Milk Proteins & 0 & 144 & 0 \\
Whey Proteins & 0 & 0 & 165 \\
Cystine & 1.8 & 0 & 0 \\
Proline & 0 & 5.7 & 4.7 \\
Rapessed oil & 30 & 30 & 30 \\
Sunflower oil & 3 & 3 & 3 \\
Peanut oil & 27 & 27 & 27 \\
Cellulose & 35 & 35 & 35 \\
Mineral mix AIN93 & 35 & 35 & 35 \\
Vitamin mix AIN93 & 10 & 10 & 10 \\
Saccharose & 100 & 100 & 100 \\
Lactose & 31 & 30 & 31 \\
Wheat Starch & 573 & 586 & 564 \\
Total Carbohydrates & $70.4 \%$ & $71.6 \%$ & $69.5 \%$ \\
Total Proteins & $13.0 \%$ & $13.0 \%$ & $13.0 \%$ \\
Total Lipids & $6.0 \%$ & $6.0 \%$ & $6.0 \%$ \\
Total Energie (kcal/kg) & 3987 & 4002 & 3998 \\
Total Essential aminoacids (g/kg diet) & & & \\
Leucine & 11.3 & 16.4 & 14.7 \\
Valine & 7.8 & 6.9 & 8.6 \\
Isoleucine & 6.1 & 6.6 & 9.2 \\
Methionine & 4.3 & 2.2 & 2.8 \\
Lysine & 9.6 & 11.1 & 11.9 \\
Tryptophan & 1.6 & 2.7 & 2.5 \\
Histidine & 3.5 & 2.4 & 2.7 \\
Threonine & 5.6 & 6.2 & 9.6 \\
Phenylalanine & 6.1 & 4.1 & 4.3 \\
\hline & & & \\
& & & \\
& & &
\end{tabular}

The evaluation of the in vivo functional properties of the plantar flexors (see below) was performed longitudinally on the same animals before and after casting in each group (Figure 1A). For the evaluation of muscle mass, muscle fibre size and muscle enzymatic properties, rats of each group were sacrificed at the different times during the immobilization period (I0 and I8) and during the recovery period (R7, R21, R35 and R49) (Figure1B). 


\section{Figure 1}

Schematic diagram of the study design. A: for the evaluation of muscle functionality and B: for the evaluation of muscle mass, muscle fibre size and muscle enzymatic properties

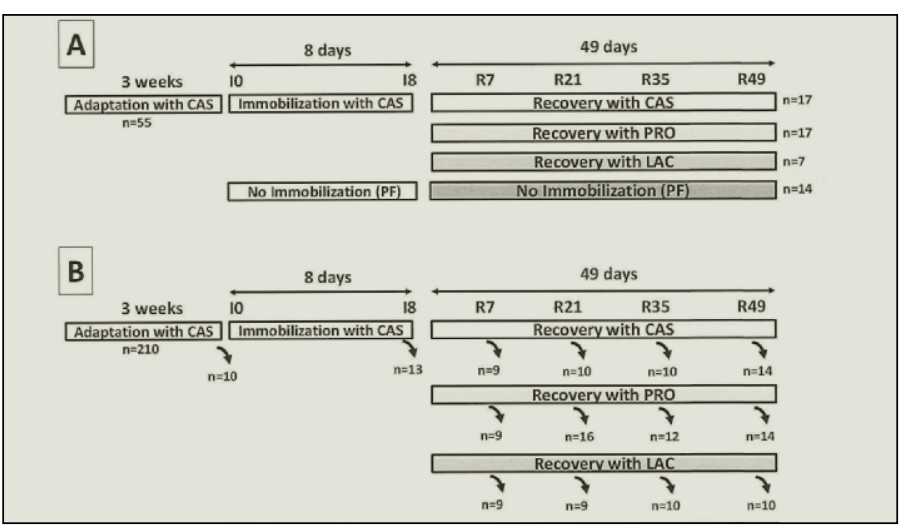

\section{Muscle masses, fibre size and biochemistry analyses}

Body mass was monitored daily all along the experimental protocol. Hindlimb muscles (soleus, gastrocnemius, extensor digitorum longus, tibialis anterior) were weighted before immobilization, after 8 days of immobilization (I8) and then 7 , 21,35 and 49 days of recovery after anaesthesia and sacrifice of the animals by aortic blood exsanguination.

Immediately after sacrifice, a part of gastrocnemius muscle was cut, included in an embedding medium (Cryomount; Histolab, Göteborg, Sweden) and mounted on a cork piece. The sample was then frozen in isopentane cooled to its freezing point in liquid nitrogen and stored at $-80^{\circ} \mathrm{C}$ until further cryostat sectioning. Gastrocnemius muscle was chosen because it is the largest plantar flexor muscle. A ten $\mu \mathrm{m}$-thick cross section was cut at $-20^{\circ} \mathrm{C}$ using a cryostat (Leica, Cryocut 1800 ), mounted on glass slides, air-dried at room temperature during 45 minutes and stored a few days at $-20^{\circ} \mathrm{C}$ until Hematoxylin-Eosin (H\&E) staining. Briefly, frozen slides were air-dried at room temperature for 30 minutes, fixed in acetone during 15 minutes, rinsed in distilled water during 5 minutes and subsequently stained in Mayer's Haematoxylin (Sigma MHS32) during 4 minutes. Slides were then rinsed 5 minutes under running tepid water and after being dried they were dipped into an alcoholic eosin Y solution (Sigma HT110132) during 1 minute. After a wash in distilled water, slides were progressively dehydrated in different baths of ethanol ( 3 min each) at 70\%, 90\% and $100 \%$ and permanently mounted with Eukitt (CML, France) and Xylene.

Images were captured with a digital camera (Leica DFC450C) connected to a microscope (Leica DM2000). Muscle fiber area was measured using Image J. software (NIH, USA) on a mean of 600 fibers randomly chosen on the whole muscle sample to provide a good estimation of mean muscle fibre area. During all muscle analysis, the technicians in charge of muscle analysis worked in a blind manner.
Citrate synthase (CS) and beta-hydroxyacyl CoA dehydrogenase ( $\beta$-HAD) activities

Frozen gastrocnemius and soleus samples were homogeneized in ice-cold extracting buffer $(175 \mathrm{mM} \mathrm{KCl}, 2$ mM EDTA, 0.1\% Triton, $\mathrm{pH}$ 7.4). CS activity was assessed according to the method of Srere et al. (38). The assay was initiated by the reaction of acetyl-CoA with oxaloacetate. The reduced $\mathrm{CoA}(\mathrm{CoA}-\mathrm{SH})$ released reacts with 5.5'-dithiobis-2nitrobenzoic acid (DTNB) and forms the coloured compound 2-nitro-5-benzoic acid (TNB). The increase of TNB absorbance was followed for 3 minutes at $412 \mathrm{~nm}$. The activity was expressed as $\mu \mathrm{mols}$ of substrate transformed per minute per $\mathrm{g}$ of wet weight.

$\beta$-HAD activity was assessed according to the method described by Essen et al. (39). Acetoacetyl-CoA was used as substrate and the disappearance of NADH was followed for 3 minutes at $355 \mathrm{~nm}$. The activity was expressed as $\mu$ moles of substrate transformed per minute per $\mathrm{g}$ of wet weight.

\section{Evaluation of the muscle functional properties}

The functional properties of the plantarflexor muscles were evaluated in vivo on an isokinetic dynamometer specially designed for rats (806D, Aurora Scientific, Canada). The testing protocol was similar to that used by Martin et al. (34).

Rats were maintained anesthetized with continuous isoflurane inhalation. During the testing procedures, the rat laid supine on a heating plate with the right foot attached to a footplate connected to a dual mode servomotor (305C-LR, Aurora Scientific, Canada). The knee was clamped in place such that the knee angle was $90^{\circ}$, and the ankle axis of rotation coincided with axis of the motor. To avoid any variation in body temperature, the rectal temperature was monitored and computed by a temperature controller (ATC 1000, World Precision Instruments, USA) that adjusted the temperature of the heating plate to maintain the rectal temperature at $37^{\circ} \mathrm{C}$. Stimulation of the rat ankle plantarflexors was done percutaneously via $\mathrm{Ag} / \mathrm{AgCl}$ surface electrodes (StimCom TS0020, Comepa, France). A constant-current electrical stimulator (DS 7A, Digitimer, United Kingdom) was used to deliver square waves (pulse width $=1 \mathrm{~ms}$ ). The stimulator was triggered and controlled with automated scripts by an A/D board (Powerlab 8/35, ADInstruments, Australia) and associated software (LabChart 7.3, ADInstruments, Australia).

The protocol consisted in the evaluation of the torquefrequency relationship in isometric condition, the torquevelocity relationship in concentric condition and the assessment of muscle fatigability in isometric condition (34).

To determine the torque-frequency curve, the ankle angle was set at $90^{\circ}$ and the plantarflexors stimulated at frequencies varying from 10 to $200 \mathrm{~Hz}(10,20,30,40,50,60,70,80,100$, $125,150,175$, and $200 \mathrm{~Hz}$ ). These contractions were $200 \mathrm{~ms}$ in length with $45 \mathrm{~s}$ between contractions, and done in order of increasing stimulation frequency. The reported isometric torque values were calculated as the peak isometric torque 
minus resting torque. The maximal torque was determined from the torque-frequency relationship. The specific torque was calculated as the maximal torque divided by muscle mass (see below).

After 3 minutes of rest, the torque-velocity curve was determined from 11 concentric contractions realized at angular velocities of 50, 100, 200, 300, 400, 500, 600, 700, 800, 900, and $1,000 \%$, realized in order of decreasing velocity. These contractions were evoked over a $40^{\circ}$-angular amplitude, centered about the $90^{\circ}$ ankle angle (i.e., from $70^{\circ}$ to $110^{\circ}$ ). This movement range was chosen because it coincides closely to that of the ankle during the stance phase of voluntary ambulation (i.e., from $72^{\circ}$ to $111^{\circ}$; [40]). The contractions were evoked every $45 \mathrm{~s}$ by stimulation trains delivered at $175 \mathrm{~Hz}$ for only the duration necessary to complete the movement (i.e., $40 \mathrm{~ms}$ at $1,000 \%$ s to $800 \mathrm{~ms}$ at $50^{\circ} / \mathrm{s}$ ); the $175-\mathrm{Hz}$ frequency was used according to Warren et al. (31) recommendation, as the frequency yielding maximal isometric tetanic torque. A powervelocity curve was then computed from this torque-velocity curve to determine the maximal power.

Finally, muscle fatigability was assessed with an isometric protocol adapted from the standard Burke fatigue protocol (41). It consisted in a repetition of $300-\mathrm{ms}$ stimulation trains at a frequency of $40 \mathrm{~Hz}$, repeated every second for 75s. Maximum and minimum isometric torque values were computed to calculate a fatigability index, as follows:

Fatigability index $(\%)=(($ minimum torque - maximal torque $) /$ maximal torque) $\mathrm{x} 100$

Data were recorded with an A/D Board (Powerlab 8/35, ADInstruments, Australia), sampled at a frequency of 2000 $\mathrm{Hz}$ and analyzed with the Labchart software (LabChart 7.3, ADInstruments, Australia). This software and the Powerlab system were also used to trigger and control the movement of the isokinetic ergometer with automated scripts during concentric contractions.

\section{Statistics}

Data are expressed in the text as mean $\pm \mathrm{SD}$, excepted in the figures where SEM has been preferred for the sake of clarity for the corresponding figures.

Data were screened for normality of distribution and homogeneity of variances using a Shapiro-Wilk normality test and the Bartlett test, respectively. Functional tests data were obtained longitudinally from the same rats. As a consequence, isometric torque, concentric power and fatigability data were analyzed with a two-way ANOVA with repeated measures (time $\mathrm{x}$ diet). When the ANOVA revealed significant effects or interaction between factors, a Fischer least significant difference post hoc test was applied to test the discrimination between means.

The muscle mass and enzymatic activities data were obtained from independent groups of rats. As a consequence, these data were analysed with a two-way ANOVA (time $\mathrm{x}$ diet). When the ANOVA revealed significant effects or interaction between factors, a Fischer least significant difference post hoc test was applied to test the discrimination between means.

The limit for statistical difference was set at $\mathrm{p}<0.05$. Statistical procedures were performed using the Statistica 8.0 software (Statsoft, Inc.).

\section{Results}

\section{Food intake and animal body weight}

Food intake was similar in all groups before casting and decreased during immobilization to reach $10.2 \pm 0.1,10.3$ \pm 0.1 and $10.4 \pm 0.1 \mathrm{~g} / \mathrm{d}$ at I8 in the CAS, PRO and LAC groups, respectively (Figure 2). Then, animals increased their food intake during the recovery period. Food intake of the PF group perfectly matched the one of the casted group during immobilization, such that food intake did not differ significantly between the 4 groups during the whole experimental period.

\section{Figure 2}

Food intake (panel A) and body weight (panel B) of casted rats fed with casein (CAS), soluble milk protein (PRO), whey proteins (LAC) and non-casted (PF) rats

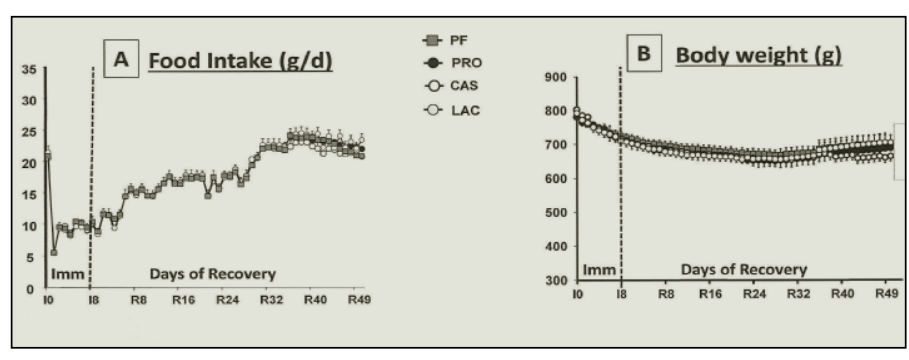

Casted rats exhibited a slight decrease of body weight during immobilization $(-12.4 \%,-8.2 \%$ and $-10.5 \%$ at I8 in the CAS, PRO and LAC groups, respectively; $p<0.05$; Figure 2). Then body weight stabilized during the recovery period for the PRO and LAC groups (I49: $-12.2 \%$ and $-11 \%$, respectively) but continued to decrease in the CAS groups (-17\% at R49) (Figure $2)$. The PF body weight followed the same modifications with a decrease at I8 and R49 of $-7.4 \%$ and $-10.3 \%$, respectively.

\section{Muscle masses}

Eight days of cast immobilization induced a significant decrease in plantar flexor muscle masses (soleus + gastrocnemius) after 8 days of unloading $(-24.9 \%, \mathrm{p}<0.0003$ vs. I0) (Figure 3A). Muscle mass also decreased progressively $(-12.8 \%$ at $\mathrm{R} 49 ; \mathrm{p}<0.05$ vs. $\mathrm{I} 0)$ in the PF group and it was probably associated with the aging process and sarcopenia development for such animals in this age range (Figure 3A). When fed the casein diet, muscle mass in the casted group remained lower when compared to the PF group $(\mathrm{p}<0.0001)$ after 7, 21 and 35 days of rehabilitation (Figure 3A and B) and muscle mass gain during rehabilitation (I8 to R49) remained 


\section{THE JOURNAL OF NUTRITION, HEALTH \& AGING@}

no significant $(\mathrm{p}<0.069)$ (Figure 3B). In contrast, when fed the soluble milk proteins (PRO) or whey proteins (LAC), a muscle mass recovery occurred and it was significantly different from the casein fed group (Figure 3B). When PRO and LAC proteins were compared, no significant difference was found in term of muscle mass recovery between the two proteins (Figure 3B).

\section{Figure 3}

A: Muscle mass of plantar flexor muscle masses (soleus + gastrocnemius) during the immobilization period and during the recovery period in rats fed the casein diet (CAS) and their pair fed controls (PF). B: muscle mass gain after immobilization in rats fed the casein (CAS), (PRO) or the (LAC).

Data are means \pm SD

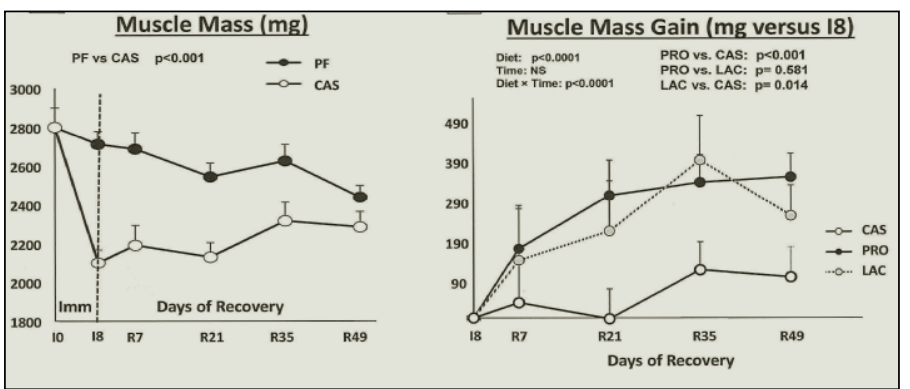

\section{Muscle Fibre area}

Eight days of cast immobilization induced a significant $19 \%$ decrease in muscle fiber area $(\mathrm{p}<0.05$, Figure 4A vs. 4B). Similarly to what was observed with muscle masses, during recovery, PRO and LAC diet induced a larger gain in muscle fiber area compared to CAS diet $(p<0.03)$, but we did not observe any significant differences between PRO and LAC (Figure 4C D E F).

\section{Citrate synthase (CS) and beta-hydroxyacyl CoA dehydrogenase $(\beta-H A D)$ activities}

\section{Immobilization effect}

Overall, at I8 the activities of both CS (Figure 5, panel A and $\mathrm{B}$ ) and $\beta$-HAD (Figure 6, panel A and B) decreased in the gastrocnemius and soleus muscles, compared to I0 and I8 Pair-fed. Pair-feeding per se only decreased CS activity in the gastrocnemius (Figure 5A, p <0.001).

\section{Recovery period}

During the recovery period, CS activity increased in both gastrocnemius (Figure 5C) and soleus (Figure 5D) muscles whatever the nutritional state of the rats (time effect, $\mathrm{p}<0.001$ ). In gastrocnemius (Figure 5C), ANOVA showed a significant group effect $(\mathrm{p}<0.001)$ and a significant interaction (group $\mathrm{x}$ time effect, $\mathrm{p}<0.001)$ indicating a greater recovery in CS activity in PRO and LAC groups compared with CAS group. Post-hoc analysis indicated that rats fed with LAC exhibited a quicker CS activity restoration after 7 days (R7) compared to PRO $(\mathrm{p}<0.01)$ or CAS $(\mathrm{p}<0.001)$ groups. After 21 days of recovery, CS activity was higher in PRO compared to CAS group $(\mathrm{p}<0.01)$. After 35 and 49 days of recovery (R35 and $\mathrm{R} 49), \mathrm{CS}$ activity was only higher in PRO group compared to LAC $(\mathrm{p}<0.001)$ or CAS $(\mathrm{p}<0.001)$.

\section{Figure 4}

Micrograph pictures showing typical changes observed on histological sections stained with Hematoxylin and Eosin (H\&E) in rat gastrocnemius muscle before (panel A) and after 8 days of immobilization (panel B). Panels C and D show muscle recovery after 21 and 49 days with CAS diet while panels $\mathrm{E}$ and

F show muscle recovery after 21 and 49 days with PRO diet

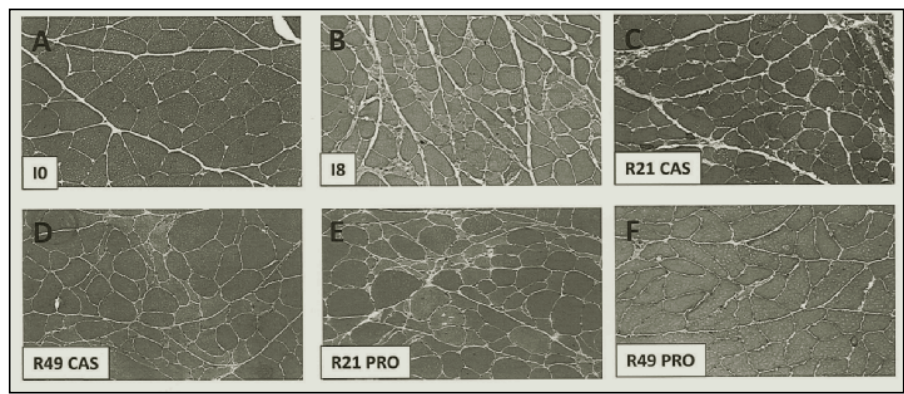

Figure 5

Gastrocnemius and soleus citrate synthase (CS) activity before (I0) and after the immobilization period in the pair fed (I8 pairfed) and the casein (I8 casein) groups (panels A and B) and during the recovery period (R7 to R49) in rats fed with casein (CAS, open circles), soluble milk proteins (PRO, Black-filled circles) and whey proteins (LAC, grey-filled circles) (panels

$\mathrm{C}$ and D). \# CAS significantly different from PRO; § CAS significantly different from LAC; * PRO significantly different from LAC

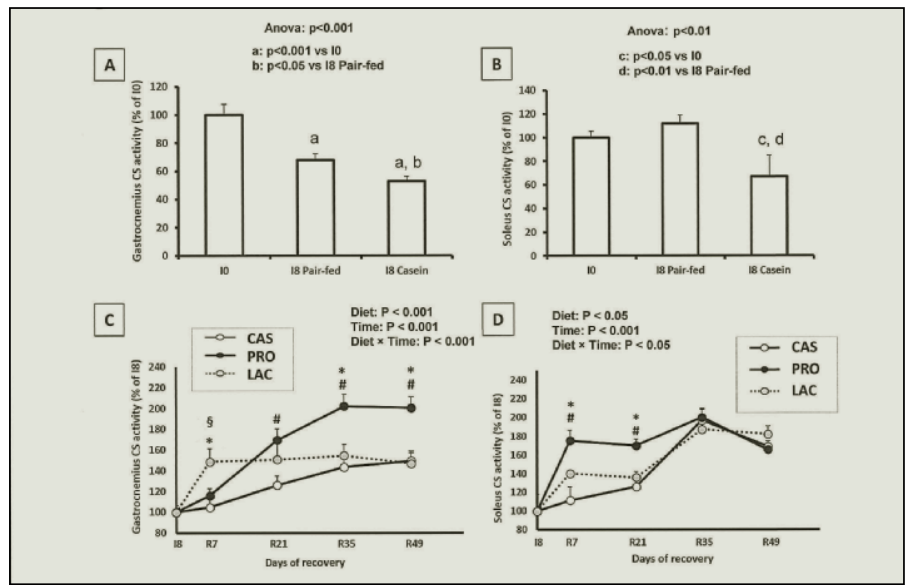

In the soleus muscle (Figure 5D), a group effect was also observed $(\mathrm{p}<0.05)$. Rats fed with PRO differed significantly from those fed with CAS $(\mathrm{p}<0.01)$ and LAC $(\mathrm{p}<0.05)$. Rats fed with LAC did not differ from those fed with CAS. Time $x$ group interaction was also significant $(\mathrm{p}<0.05)$ and post-hoc analysis indicated a higher CS activity in rats fed with PRO at 


\section{SOLUBLE MILK PROTEINS IMPROVE MUSCLE MASS RECOVERY AFTER IMMOBILIZATION-INDUCED MUSCLE}

R7 and R21 compared to both CAS and LAC.

Considering $\beta$-HAD activity, ANOVA indicated a significant group effect $(\mathrm{p}<0.001)$ and a significant time $\mathrm{x}$ group effect $(\mathrm{p}<0.001)$ in the gastrocnemius (Figure 6C). Rats fed with PRO or LAC showed a higher $\beta$-HAD activity compared to the CAS group ( $\mathrm{p}<0.001$ for PRO vs. CAS and $\mathrm{p}<0.05$ for LAC vs. CAS). After 7 and 21 days of recovery, rats fed with PRO already presented a higher $\beta$-HAD activity compared to CAS and LAC. In contrast, the PRO and LAC groups showed a higher $\beta$-HAD activity compared to CAS group after 35 and 49 days of recovery. In the soleus (Figure $6 \mathrm{D})$, rats fed with both PRO and LAC showed a higher $\beta$-HAD activity compared to rats fed with Casein $(\mathrm{p}<0.01)$. Group $\mathrm{x}$ time interaction effect was also noted $(\mathrm{p}<0.01)$. PRO group showed higher $\beta$-HAD activity compared to CAS group at all recovery time. LAC group showed higher $\beta$-HAD activity compared to CAS group at R7, R21 and R49.

\section{Figure 6}

Gastrocnemius and soleus beta-hydroxyacyl CoA dehydrogenase ( $\beta$-HAD) activity before (I0) and after the immobilization period in the pair fed (I8 pair-fed) and the casein (I8 casein) groups (panels A and B) and during the recovery period (R7 to R49) in rats fed with casein (CAS, open circles), soluble milk proteins (PRO, Black-filled circles) and whey proteins (LAC, grey-filled circles) (panels C and D). \# CAS significantly different from PRO; § CAS significantly different from LAC; * PRO significantly different from LAC

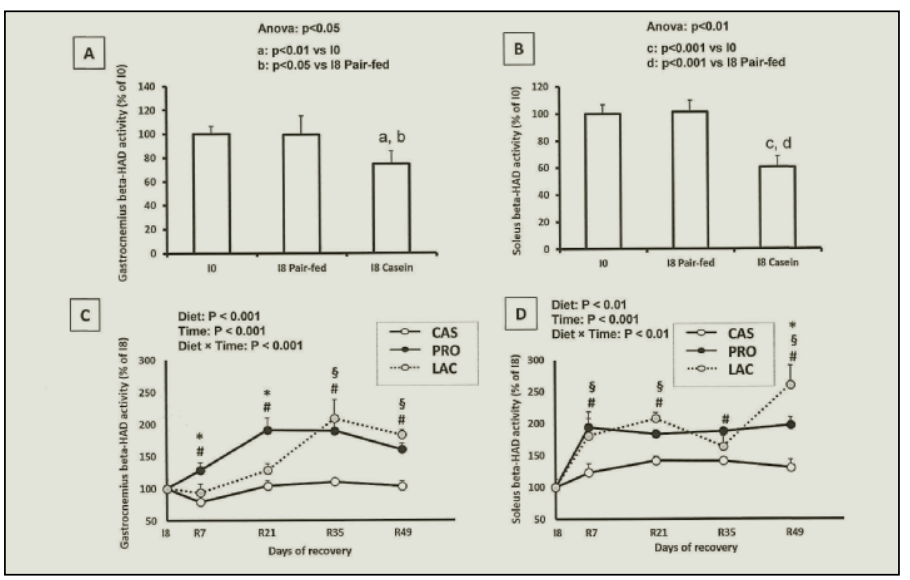

\section{Functional properties}

The maximal isometric torque was reduced at $\mathrm{I} 8$ in the immobilized groups as compared to $\mathrm{PF}(\mathrm{p}<0.05$; Figure $7 \mathrm{~A})$. $\mathrm{PF}$ maximal isometric then tended to decline over time and this decline became significant at R35 and R49. The immobilized groups partly recovered between R7 and R21, such that the isometric torque was not different from $\mathrm{PF}$ in the immobilized groups between R7 and R49. No significant difference was observed between the CAS, LAC and PRO groups.

Finally, the fatigability index also varied over time but did not differ between groups. The fatigability index decreased at
I8 ( $\mathrm{p}<0.001$; Figure 6C) and then gradually increased until $\mathrm{R} 49$. On average, at R35 and R49, the fatigability index had improved as compared to I0 ( $\mathrm{p}<0.001)$.

\section{Figure 7}

A) Maximal torque produced by the plantarflexor muscles before (I0), immediately after (I8) and 7 (R7), 21 (R21), 35 (R35) and 49 days (R49) after an eight-day immobilization period. Torque was measured in experimental groups fed a casein (open circles), LAC (grey-filled circles) or PRO diet (Black-filled circles). Torque was also measured in a pair-fed group (grey-filled square). Significantly different from I0: $* * *: \mathrm{P}<0.001$. Significantly different from PF: $\S: \mathrm{P}<0.05$.

B) Maximal concentric power produced by the plantarflexor muscles before (I0), immediately after (I8) and 7 (R7),

21 (R21), 35 (R35) and 49 days (R49) after an eight-day immobilization period. Power was measured in experimental groups fed a casein (open circles), LAC (grey-filled circles) or PRO diet (Black-filled circles). Power was also measured in a pair-fed group (grey-filled square). Significantly different from I0: ***: $\mathrm{P}<0.001$. Significantly different from I8: $£ £: \mathrm{P}<0.01$. Significantly different from R21: $\$: P<0.05$. C) Fatigability index of the plantarflexor muscles before (I0), immediately after (I8) and 7 (R7), 21 (R21), 35 (R35) and 49 days (R49) after an eight-day immobilization period. Fatigability was measured in experimental groups fed a casein (open circles), LAC (grey-filled circles) or PRO diet (Black-filled circles). Fatigability was also measured in a pair-fed group (grey-filled square). Significantly different from I0: $* * *: \mathrm{P}<0.001$.

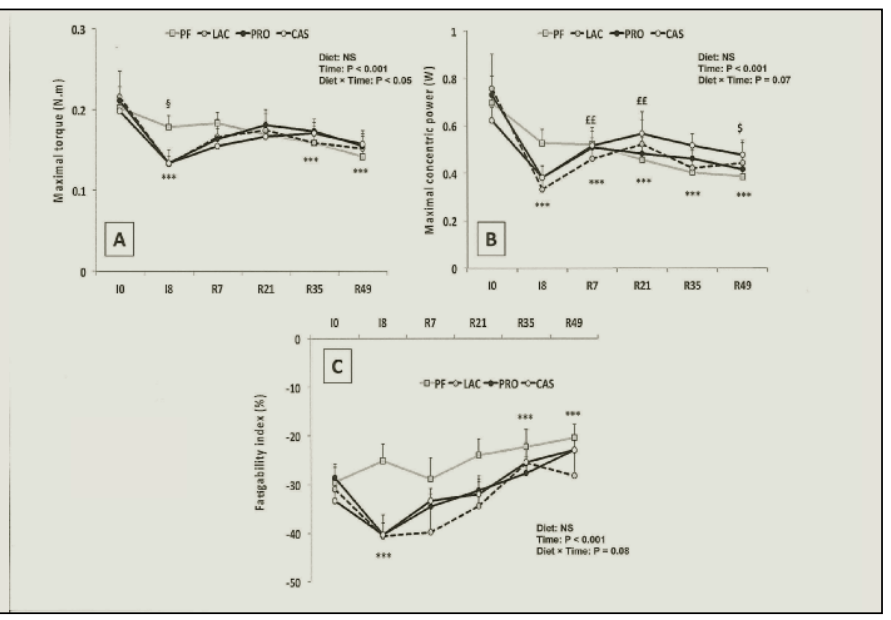

The maximal specific torque varied as function of time but not differ between groups. It declined at I8 $(-10.9 \%, \mathrm{P}<0.01$ vs. I0), recovered at R7 and R21, and then declined at R35 $(-7.6 \%, \mathrm{p}<0.05$ vs. I0) and R49 (-12.1\%, p < 0.001 vs. I0).

The maximal concentric power varied over time but did not differ between groups. Maximal power was reduced from I8 to R49 ( $\mathrm{p}<0.001$ vs. I0; Figure 7B). A partial recovery was observed at R7 and R21, and then power declined from R35 to R49. At R49, the maximal power had significantly decreased as 


\section{THE JOURNAL OF NUTRITION, HEALTH \& AGING@}

compared to R21 ( $\mathrm{p}<0.05)$.

\section{Discussion}

The aim of the present study was to compare the beneficial effect of three milk proteins i.e. casein, soluble milk proteins and whey proteins on the recovery of skeletal muscle mass, force, power and fatigability after cast immobilisation during aging. In this study, we observed that in contrast to the casein diet, soluble milk proteins and whey proteins were efficient to favor muscle mass recovery after cast immobilization during aging. However, none of the 3 diary proteins was able to improve muscle strength, power and fatigability showing a discrepancy between the recovery of muscle mass and function. However, the soluble milk proteins improved the oxidative capacity in skeletal muscle during the rehabilitation period.

\section{Muscle Mass during immobilization and subsequent recovery}

As we previously showed (4-5), cast immobilization was associated with muscle atrophy which was not significantly reversed after the cast removal when casein was used as the dietary protein source. In contrast, with the same amount of soluble milk proteins (soluble milk proteins or whey proteins), a significant increase of muscle mass was observed over the 49 days of recovery A recovery of about $40 \%$ of the muscle mass loss was reached with no difference in the effect of the two soluble milk protein sources studied. The positive effect of soluble milk proteins compared to casein was attributed not only to their higher digestion speed rate but mainly to their higher leucine content (42-45). Indeed, leucine has been shown to trigger an anabolic signal toward muscle protein synthesis $(17,46)$ which allows a better stimulation of muscle protein synthesis after food intake, especially in anabolic resistance situations (30) including skeletal muscle immobilization $(47,5)$. A better post prandial muscle protein synthesis could be then more efficient in restoring muscle myofibrillar protein content and fibre size during the recovery period. In the present study, a decrease of muscle fibre area during immobilization paralleled muscle atrophy $(-19 \%$ and $-25 \%)$ and muscle recovery was indeed associated with a significant larger gain in muscle fibre area with both soluble milk proteins tested. On these two parameters, no difference between soluble milk proteins (PRO) or whey proteins (LAC) was observed.

\section{Muscle functional properties}

It may be postulated that a modification of muscle mass is necessarily associated with a proportional modification of muscle contractile properties, i.e. muscle power and strength. However, in several situations, muscle mass and force/power production capacities are not always linearly related (31-33) even in elderly (35). It is also the case in the present study as the loss in muscle maximal torque and concentric power were higher than the decrease in muscle mass during the immobilization period (-33\% and $-50 \%$ vs. $-25 \%)$. Interestingly, in younger adults, with the same model of immobilization, we showed that the decrease of muscle torque and power were similar to the decrease of muscle mass; i.e. $20-25 \%(4,34)$. It can be then hypothesized that the discrepancy between muscle mass and contractile properties is accentuated with age. In the present study, it was also the case during the recovery period as the significant recovery of muscle mass with the two soluble milk proteins tested was not associated with a paralleled modification of muscle strength or power. Such a decoupling has been previously reported in the literature. Papadakis et al. (32) observed, after a GH treatment in elderly men, an increase in muscle mass but not in knee or handgrip strength. Likewise, the meta-analysis of Komar et al. (35) concluded that leucine rich protein supplementation was found to exert beneficial effects on lean body mass but not on muscle strength in the elderly. An explanation of this phenomenon could be that immobilization is known to induce a remodeling of collagen network that would alter extracellular matrix mechanical properties and induce a decrease in force transmission (48). Another possibility could be an inability to recover an appropriate myofibrillar density. Indeed, it has been shown that both aging and unloading generate a decrease in myosin concentration, i.e. a disproportionate loss of myosin content with respect to CSA of muscle fibres (49).

\section{Muscle mitochondrial enzyme activities}

Recently, Gryson et al. (37) showed that soluble milk proteins rich in leucine delayed time to muscle failure i.e. muscle fatigability in healthy older volunteers following a prolonged exercise program. It has been known for a long time that fatigue resistance is highly correlated with mitochondrial enzyme activity (50-51). As expected, we observed decreased enzyme activities following 8 days of immobilization (52-53). During the recovery period, a time-effect showed an improved activity of $\beta$-HAD and CS in both soleus and gastrocnemius. Oishi et al. demonstrated similar results in growing rats (54). These authors indeed showed an increase of COX-IV protein content (another marker of mitochondrial density) during the recovery period following two weeks of hindlimb unloading. Interestingly, our result showed that compared to CAS, PRO and LAC induced a better enzyme activity recovery except for soleus CS activity which was only improved in PRO compared to CAS group. These results showed that soluble milk proteins may have some beneficial effects on oxidative capacity recovery following immobilization. We might hypothesize that the greater amount of leucine in soluble milk proteins may account for the beneficial effects of PRO and LAC compared to CAS as leucine has been shown to stimulate mitochondrial biogenesis on $\mathrm{C} 2 \mathrm{C} 12$ myocytes (55) and increases SIRT1 expression leading to an improvement of mitochondrial function in mice (56-57). In some cases, PRO presented better recovery effects than LAC. Compared to baseline, the recovery of $\beta$-HAD activity in gastrocnemius muscle and CS activity in 


\section{SOLUBLE MILK PROTEINS IMPROVE MUSCLE MASS RECOVERY AFTER IMMOBILIZATION-INDUCED MUSCLE}

soleus muscle was indeed faster with PRO, while CS activity in gastrocnemius muscle reached higher levels only at the end of the recovery period in the PRO group. More studies appear necessary in this context to understand why soluble milk proteins (PRO) may improve enzymatic activities to a better extent than whey proteins (LAC).

Despite these observations on enzyme activities, no differences in fatigue resistance were noted between the three diets during the recovery period. Two hypotheses can be proposed to explain this apparent discrepancy. First of all, even if $\beta$-HAD and CS activities are considered as good makers of global oxidative capacity, one could hypothesize that functional properties of mitochondria, not measured in the present study, did not change in the same extent than $\beta$-HAD and CS activities (58). A second hypothesis would be that mitochondrial oxidative capacity is not the limiting factor of skeletal muscle fatigability and that other important mechanisms might occur. Fatigue mechanisms are indeed very complex and may include different causative factors depending on the type of fatiguing task (59). The relative short measurement period used to assess fatigability index in the present study (75s), may direct assumptions towards other physiological mechanisms than mitochondrial oxidative capacity to explain fatigability results, such as excitation-contraction coupling for example. One could then hypothesize that a longer fatigue protocol requiring a significant contribution of the oxidative metabolism, might highlight a significant difference between the several diets used in the present study.

In conclusion, the present study showed that while soluble milk proteins were more efficient in promoting muscle mass recovery after muscle immobilization during aging, they remained inefficient for the restoration of muscle functionality such as strength, power or fatigability. However, because soluble milk proteins and especially the ones extracted directly from milk showed a better recovery of the muscle oxidative capacities, it might be suggested that exercise training should be performed concomitantly with the nutritional strategy to optimize the effect of soluble milk proteins on both muscle mass and function recovery in elderlies.

Acknowledgments: The authors are grateful to A. Cissoire, P. Lhoste, M. Jarzaguet and G. Grateau for their technical assistance during the experiments. Proteins were kindly provided by Lactalis, Retiers, France.

Conflict of Interest: ?????

\section{References}

1. Harris T. .Muscle mass and strength:relation to function in population studies. J Nutr, 1997, 127,1004S-1006S

2. Chakravarthy MV, Davis BS \& Booth FW. IGF-I restores satellite cell proliferative potential in immobilized old skeletal muscle. J Appl Physiol 2000;89, 1365-1379.

3. Suetta C, Hvid LG, Justesen L, Christensen U, Neergaard K, Simonsen L, Ortenblad N, Magnusson SP, Kjaer M , Aagaard P. Effects of ageing on human skeletal muscle after immobilization and retraining. J Appl Physiol, 2009, 107, 1172-1180.

4. Magne H, Savary-Auzeloux I, Vazeille E, Claustre A, Attaix D, Listrat A, Veronique SL, Philippe G, Dardevet D, Combaret L. Lack of muscle recovery after immobilization in old rats does not result from a defect in normalization of the ubiquitin-proteasome and the caspase-dependent apoptotic pathways. J Physiol, 2011, $589,511-524$
5. Magne H, Savary-Auzeloux I, Migne C, Peyron MA, Combaret L, Remond $\mathrm{D}$, Dardevet D. Contrarily to whey and high protein diets, dietary free leucine supplementation cannot reverse the lack of recovery of muscle mass after prolonged immobilization during ageing. J Physiol 2012;590: 2035-2049.

6. Magne H, Savary-Auzeloux I, Remond D, Dardevet D. Nutritional strategies to counteract disuse muscle atrophy and improve following recovery. Nutrition Research Reviews 2013 Aug 9:1-17

7. Kortebein P, Ferrando A, Lombeida J, Wolfe R, Evans WJ. Effect of 10 days of bed rest on skeletal muscle in healthy older adults. Jama 2007;297, 1772-1774

8. English KL \& Paddon-Jones D. Protecting muscle mass and function in older adults during bed rest. Current opinion in clinical nutrition and metabolic care 2010;13, 34-39.

9. Ferrucci L, Cavazzini C, Corsi A, Bartali B, Russo CR, Lauretani F, Ferrucci L, Cavazzini C, Corsi AM, Bartali B, Russo CR, Lauretani F, Bandinelli S, Bandinelli S, Guralnik JM. Biomarkers of frailty in older persons. J Endocrinol Invest. 2002;25(10 Suppl):10-5.

10. Cooper R, Kuh D, Cooper C, Gale CR, Lawlor DA, Matthews F, Hardy R; FALCon and HALCyon Study Teams. Objective measures of physical capability and subsequent health: a systematic review. Age Ageing. 2011 Jan;40(1):14-23

11. Rieu, I., Sornet, C., Grizard, J., Dardevet, D. Glucocorticoid excess induces a prolonged leucine resistance on muscle protein synthesis in old rats. Experimental Gerontology, 2004, 39, 1315-1321.

12. Mosoni L, Malmezat T, Valluy MC, Houlier ML \& Mirand PP. Muscle and liver protein synthesis adapt efficiently to food deprivation and refeeding in 12-month-old rats. J Nutr, 1996, 126, 516-522.

13. Dardevet D, Sornet C, Taillandier D, Savary I, Attaix D \& Grizard J. Sensitivity and protein turnover response to glucocorticoids are different in skeletal muscle from adult and old rats. Lack of regulation of the ubiquitin-proteasome proteolytic pathway in ageing. The Journal of clinical investigation 1995;96, 2113-2119.

14. Anthony JC, Anthony TG, Layman DK. Leucine supplementation enhances skeletal muscle recovery in rats following exercise. J Nutr 1999;129: 1102-1106.

15. Anthony TG, Anthony JC, Yoshizawa F, Kimball SR, Jefferson LS. Oral administration of leucine stimulates ribosomal protein mRNA translation but not global rates of protein synthesis in the liver of rats. J Nutr 2001;131: 1171-1176.

16. Koopman R, Wagenmakers AJ, Manders RJ, Zorenc AH, Senden JM, Gorselink M, Keizer HA, van Loon LJ. Combined ingestion of protein and free leucine with carbohydrate increases postexercise muscle protein synthesis in vivo in male subjects. Am J Physiol Endocrinol Metab 2005;288: E645-E653.

17. Buse MG, Reid SS. Leucine. A possible regulator of protein turnover in muscle. J Clin Invest 1975;56: 1250-1261.

18. Combaret L, Dardevet D, Rieu I, Pouch MN, Bechet D, Taillandier D, Grizard J, Attaix D. A leucine-supplemented diet restores the defective postprandial inhibition of proteasome-dependent proteolysis in aged rat skeletal muscle. J Physiol 2005;569: 489-499.

19. Dardevet D, Sornet C, Bayle G, Prugnaud J, Pouyet C, Grizard J. Postprandial stimulation of muscle protein synthesis in old rats can be restored by a leucinesupplemented meal. J Nutr 2002;132: 95-100.

20. Frexes-Steed M, Lacy DB, Collins J, Abumrad NN. Role of leucine and other amino acids in regulating protein metabolism in vivo. Am J Physiol 1992;262: E925-E935.

21. Katsanos CS, Kobayashi H, Sheffield-Moore M, Aarsland A, Wolfe RR; Aging is associated with diminished accretion of muscle proteins after the ingestion of a small bolus of essential amino acids. Am J Clin Nutr 2005;82: 1065-1073.

22. Li JB, Jefferson LS (1978) Influence of amino acid availability on protein turnover in perfused skeletal muscle. Biochim Biophys Acta 544: 351-359. 0304-4165(78)901034

23. Nakashima K, Ishida A, Yamazaki M, Abe H. Leucine suppresses myofibrillar proteolysis by down-regulating ubiquitin-proteasome pathway in chick skeletal muscles. Biochem Biophys Res Commun 2005;336: 660-666.

24. Rieu I, Balage M, Sornet C, Giraudet C, Pujos E, Grizard J, Mosoni L, Dardevet D. Leucine supplementation improves muscle protein synthesis in elderly men independently of hyperaminoacidaemia. J Physiol 2006;575: 305-315.

25. Smith K, Barua JM, Watt PW, Scrimgeour CM, Rennie MJ. Flooding with L-[1-13C] leucine stimulates human muscle protein incorporation of continuously infused L-[113Clvaline. Am J Physiol 1992;262: E372-E376.

26. Tischler ME, Desautels M, Goldberg AL. Does leucine, leucyl-tRNA, or some metabolite of leucine regulate protein synthesis and degradation in skeletal and cardiac muscle? J Biol Chem 1982;257: 1613-1621.

27. Anthony JC, Anthony TG, Kimball SR, Vary TC, Jefferson LS. Orally administered leucine stimulates protein synthesis in skeletal muscle of postabsorptive rats in association with increased eIF4F formation. J Nutr 2000;130: 139-145.

28. Atherton PJ, Etheridge T, Watt PW, Wilkinson D, Selby A, Rankin D, Smith K, Rennie MJ. Muscle full effect after oral protein: time-dependent concordance and discordance between human muscle protein synthesis and mTORC1 signaling. Am J Clin Nutr 2010;92: 1080-1088.

29. Peyrollier K, Hajduch E, Blair AS, Hyde R, Hundal HS. L-leucine availability regulates phosphatidylinositol 3-kinase, p70 S6 kinase and glycogen synthase kinase-3 activity in L6 muscle cells: evidence for the involvement of the mammalian target of rapamycin (mTOR) pathway in the L-leucine-induced up-regulation of 


\section{THE JOURNAL OF NUTRITION, HEALTH \& AGING@}

system A amino acid transport. Biochem J 2000;350 Pt 2: 361-368.

30. Dardevet D, Remond D, Peyron MA, Papet I, Savary-Auzeloux I, et al. Muscle wasting and resistance of muscle anabolism: the «anabolic threshold concept» for adapted nutritional strategies during sarcopenia. ScientificWorldJournal 2012: 269531.

31. Warren GL, Stallone JL, Allen MR, Bloomfield SA.Functional recovery of the plantarflexor muscle group after hindlimb unloading in the rat. Eur J Appl Physiol 2004;93: 130-138.

32. Papadakis MA, Grady D, Black D, Tierney MJ, Gooding GA, et al. Growth hormone replacement in healthy older men improves body composition but not functional ability. Ann Intern Med 1996;124: 708-716.

33. Hughes VA, Frontera WR, Wood M, Evans WJ, Dallal GE, Roubenoff R \& Fiatarone Singh MA. Longitudinal muscle strength changes in older adults: influence of muscle mass, physical activity, and health. The journals of gerontology 2001;56, B209-217.

34. Martin V, S Ratel, J Siracusa, P. Leruyet, I Savary-Auzeloux, L Combaret, C Guillet and D Dardevet. Leucine-rich proteins are more efficient than casein in the recovery of muscle functional properties following a casting induced muscle atrophy. PlosOne, 2013a, Sep 19;8(9):e75408

35. Komar B, Schwingshackl L, Hoffmann G. Effects of leucine-rich protein supplements on anthropometric parameter and muscle strength in the elderly: a systematic review and meta-analysis. J Nutr Health Aging. 2015 Apr;19(4):437-46

36. Martin V, S. Ratel, J. Siracusa, C. Bonhomme, L. Combaret, I. Savary-Auzeloux, C Guillet, D. Dardevet. Les protéines solubles de lait accélèrent la récupération des aptitudes fonctionnelles musculaires à la suite d'une immobilisation. 10ème Journées Francophones de Nutrition, Lyon (France). Nutrition Clinique et Métabolisme, Cahiers de Nutrition et de Diététique , 2013b;26-47, S27.

37. Gryson C, Ratel S, Rance M, Penando S, Bonhomme C, Le Ruyet P, Duclos M, Boirie Y, Walrand S. Four-month course of soluble milk proteins interacts with exercise to improve muscle strength and delay fatigue in elderly participants. J Am Med Dir Assoc. 2014 Dec;15(12):958

38. Srere PA .Citrate synthase.Methods Enzymol. 1969, 13, :3-11,

39. Essén B, Jansson E, Henriksson J, Taylor AW, Saltin B. Metabolic characteristics of fibre types in human skeletal muscle. Acta Physiol Scand. 1975 Oct;95(2):153-65.

40. Varejao AS, Cabrita AM, Meek MF, Bulas-Cruz J, Gabriel RC, et al. Motion of the foot and ankle during the stance phase in rats. Muscle Nerve 2002;26: 630-635

41. Burke RE, Levine DN, Tsairis P, Zajac FE, 3rd; Physiological types and histochemical profiles in motor units of the cat gastrocnemius. J Physiol 1973;234: 723-748

42. Boirie Y, Dangin M, Gachon P, Vasson MP, Maubois JL, et al. Slow and fast dietary proteins differently modulate postprandial protein accretion. Proc Natl Acad Sci U S A 1997;94: 14930-14935.

43. Dangin M, Boirie Y, Garcia-Rodenas C, Gachon P, Fauquant J, et al. The digestion rate of protein is an independent regulating factor of postprandial protein retention. Am J Physiol Endocrinol Metab 2001;280: E340-348.

44. Rieu I, Balage M, Sornet C, Debras E, Ripes S, Rochon-Bonhomme C, Pouyet C, Grizard J, Dardevet D. Increased availability of leucine with leucine-rich whey proteins improves postprandial muscle protein synthesis in aging rats Nutrition. 2007 Apr;23(4):323-31
45. Pennings B, Boirie Y, Senden JM, Gijsen AP, Kuipers H, van Loon LJ.; Whey protein stimulates postprandial muscle protein accretion more effectively than do casein and casein hydrolysate in older men. Am J Clin Nutr. 2011 May;93(5):9971005

46. Dardevet D, Sornet C, Balage M, Grizard J. Stimulation of in vitro rat muscle protein synthesis by leucine decreases with age. J Nutr 2000;130: 2630-2635.

47. Glover EI, Phillips SM, Oates BR, Tang JE, Tarnopolsky MA, Selby A, Smith K \& Rennie MJ. Immobilization induces anabolic resistance in human myofibrillar protein synthesis with low and high dose amino acid infusion. The Journal of physiology 2008;586, 6049-6061.

48. Järvinen TA, Józsa L, Kannus P, Järvinen TL, Järvinen M. Organization and distribution of intramuscular connective tissue in normal and immobilized skeletal muscles. An immunohistochemical, polarization and scanning electron microscopic study. J Muscle Res Cell Motil. 2002;23(3):245-54.

49. Canepari M, Pellegrino MA, D'Antona G, Bottinelli R. Skeletal muscle fibre diversity and the underlying mechanisms. Acta Physiol (Oxf). 2010 Aug;199(4):46576.2010

50. Holloszy JO. Biochemical adaptations in muscle. Effects of exercise on mitochondrial oxygen uptake and respiratory enzyme activity in skeletal muscle. J Biol Chem. 1967 May 10;242(9):2278-82.

51. Terjung RL, Baldwin KM, Molé PA, Klinkerfuss GH, Holloszy JO. Effect of running to exhaustion on skeletal muscle mitochondria: a biochemical study. Am J Physiol. 1972 Sep;223(3):549-54

52. Wagatsuma A, Kotake N, Kawachi T, Shiozuka M, Yamada S, Matsuda R. Mitochondrial adaptations in skeletal muscle to hindlimb unloading. Mol Cell Biochem. 2011 Apr;350(1-2):1-11. 2010 Dec 17.

53. Wall BT1, Dirks ML, Snijders T, Stephens FB, Senden JM, Verscheijden ML, van Loon LJ. Short-term muscle disuse atrophy is not associated with increased intramuscular lipid deposition or a decline in the maximal activity of key mitochondrial enzymes in young and older males. Exp Gerontol. 2015 Jan;61:76-83, 2014

54. Oishi Y, Ogata T, Yamamoto KI, Terada M, Ohira T, Ohira Y, Taniguchi K, Roy RR. Cellular adaptations in soleus muscle during recovery after hindlimb unloading. Acta Physiol (Oxf). 2008 Mar;192(3):381-95. Epub 2007 Sep 24.

55. Sun X, Zemel MB. Leucine modulation of mitochondrial mass and oxygen consumption in skeletal

56. Liu J, Peng Y, Cui Z, Wu Z, Qian A, Shang P, Qu L, Li Y, Liu J, Long J. Depressed mitochondrial biogenesis and dynamic remodeling in mouse tibialis anterior and gastrocnemius induced by 4 -week hindlimb unloading.

57. Wei-jian Jiang. Sirtuins: Novel targets for metabolic disease in drug development. Biochem Biophys Res Commun. 2008 Aug 29;373(3):341-4

58. Lantier L, Fentz J, Mounier R, Leclerc J, Treebak JT, Pehmøller C, Sanz N, Sakakibara I, Saint-Amand E, Rimbaud S, Maire P, Marette A, Ventura-Clapier R, Ferry A, Wojtaszewski JF, Foretz M, Viollet B. AMPK controls exercise endurance, mitochondrial oxidative capacity, and skeletal muscle integrity. FASEB J. 2014 Jul;28(7):3211-24

59. Westerblad H, Bruton JD, Katz A. Skeletal muscle: energy metabolism, fiber types, fatigue and adaptability. Exp Cell Res. 2010 Nov 1;316(18):3093-9. 
SOLUBLE MILK PROTEINS IMPROVE MUSCLE MASS RECOVERY AFTER IMMOBILIZATION-INDUCED MUSCLE 